\title{
Industrialização e desenvolvimento: um estudo dos municípios de Goiatuba (GO) e Morrinhos (GO) na década de 2000
}

\author{
Anne Kelly Aparecida de Souza Tassara \\ Centro Universitário de Goiatuba (UNICERRADO) \\ Moacir José dos Santos \\ Mestrado em Planejamento e Desenvolvimento Regional / Universidade de Taubaté (MPDR/UNITAU) \\ Edson Trajano Vieira \\ Mestrado em Planejamento e Desenvolvimento Regional / Universidade de Taubaté (MPDR/UNITAU)
}

Recebido: 20/02/2019 Versão revisada (entregue): 27/04/2020 Aprovado: 19/05/2020

\begin{abstract}
Resumo
O presente artigo teve como objetivo verificar os efeitos da industrialização nos municípios de Goiatuba (GO) e Morrinhos (GO), isto é, se a industrialização refletiu positivamente no crescimento e desenvolvimento desses municípios do estado de Goiás, no Centro-Oeste brasileiro, na década de 2000. O estudo que deu origem a este artigo foi realizado a partir de pesquisa descritiva, bibliográfica, documental e qualitativa, com a avaliação dos resultados mediante a comparação dos dados coletados para o período entre 2000 e 2010. Os resultados encontrados permitem demonstrar que a industrialização foi imprescindível para o crescimento econômico do município de Morrinhos naquela década. Entretanto, em relação ao município de Goiatuba, as evidências indicam que a industrialização não foi um fator crucial para o seu desenvolvimento no mesmo período.
\end{abstract}

Palavras-chave | Goiás; indicadores socioeconômicos; industrialização; planejamento e desenvolvimento regional.

Código JEL | L23 O14 R11

Industrialization and development: a study of the municipalities of Goiatuba (GO) and Morrinhos (GO) in the decade of 2000

\begin{abstract}
The present article had as purpose to verify the effects of industrialization in the municipalities of Goiatuba (GO) and Morrinhos (GO), that is, if the industrialization reflected positively in the growth and development of these municipalities of Goiás, in the Brazilian Midwest, in the decade of 2000. The study that gives origin to this article was developed from descriptive,
\end{abstract}


bibliographical, and qualitative research, with the evaluation of results by comparing the data collected between 2000 and 2010. The results found allow us to demonstrate that the industrialization was essential for the economic growth in Morrinhos in that decade. However, in relation to the Goiatuba, the evidence indicates that industrialization was not a crucial factor for its development in the same period.

Keywords | Goiás; industrialization; regional planning and development; socioeconomic indicators.

JEL-Code | L23 O14 R11

\section{Industrialización y desarrollo: un estudio de los municipios de Goiatuba (GO) y Morrinhos (GO) en la década de 2000}

\section{Resumen}

El presente artículo tuvo como objetivo verificar los efectos de la industrialización en los municipios de Goiatuba (GO) y Morrinhos (GO), esto es, si la industrialización se expresó positivamente en el crecimiento y desarrollo de esos municipios del estado de Goiás, en el centro-oeste brasileño, en la década de 2000. El estudio que dio origen a este artículo se realizó a partir de investigación descriptiva, bibliográfica, documental y cualitativa, con la evaluación de los resultados mediante la comparación de los datos recolectados del período entre 2000 y 2010. Los resultados encontrados demuestran que la industrialización fue imprescindible para el crecimiento económico del municipio de Morrinhos en aquella década. Sin embargo, en relación al municipio de Goiatuba, la evidencia muestra que la industrialización no fue un factor crucial para su desarrollo en el mismo período.

Palabras clave | Goiás; indicadores socioeconómicos; industrialización; planificación y desarrollo regional.

Codigo JEL | L23 O14 R11

\section{Introdução}

Crescimento e desenvolvimento econômico são termos frequentemente debatidos nos estudos acadêmicos em diversas áreas do conhecimento científico de forma interdisciplinar. São frequentes no cotidiano, seja nos discursos políticos ou em comunicados informativos que a imprensa repassa à população. Esses dois conceitos são geralmente confundidos quanto às suas significações. Assim, compreendê-los, e ainda relacioná-los com a industrialização, é de suma importância para verificar se determinada região apresentou crescimento ou desenvolvimento, ou se ambos ocorreram (VIEIRA; SANTOS, 2012). 
Vieira (2009) expôs que o tema desenvolvimento tem suscitado na comunidade acadêmica muito mais perguntas do que respostas, pois, o desenvolvimento econômico gera questões sobre como mensurá-lo quanto à oferta de bens e serviços, o impacto da elevação da produtividade da economia em relação às inovações, a quantificação do desenvolvimento econômico, a aplicação de indicadores como a renda per capita e o Índice de Desenvolvimento Humano (IDH).

Santos et al. (2012) definem o desenvolvimento a partir de uma concepção multidimensional e interdisciplinar, como um dos mais complexos fenômenos para se conceituar. Ressaltam, no entanto, a importância da função social que o desenvolvimento representa para a sociedade, principalmente no que diz respeito ao bem-estar humano.

Diante disso, esta pesquisa teve como foco o estudo de dois municípios goianos, Goiatuba e Morrinhos, pertencentes à microrregião do Rio Meia Ponte (GO), com a verificação da industrialização e do desenvolvimento regional na década de 2000 . $\mathrm{O}$ objetivo da pesquisa foi verificar o crescimento e o desenvolvimento econômico relacionados com o processo de industrialização, para aferir a sua contribuição quanto à melhoria dos indicadores que demonstram a qualidade de vida das populações pertencentes aos municípios de Goiatuba e Morrinhos.

A industrialização impacta o setor econômico ao provocar alterações nos indicadores econômicos como o Produto Interno Bruto (PIB), que representa a soma, em valores monetários, de todos os bens e serviços finais produzidos numa determinada região durante um certo período. São recolhidos também aos cofres públicos os tributos gerados pelas atividades industriais, destacando-se o Imposto Sobre Serviços de Qualquer Natureza (ISSQN), pertencente à esfera municipal, o Imposto sobre Produtos Industrializados (IPI), referente à esfera federal e o Imposto sobre Operações Relativas à Circulação de Mercadorias e sobre Prestações de Serviços de Transporte Interestadual, Intermunicipal e de Comunicação (ICMS), tocante à esfera estadual (BRASIL, 1966).

Além de analisar os indicadores econômicos, esta pesquisa apresenta os indicadores de desenvolvimento e as políticas públicas com o propósito de verificar a melhoria da qualidade de vida da população dos municípios de Goiatuba (GO) e Morrinhos (GO), na década de 2000, relacionada com a quantidade de indústrias instaladas nesses municípios, durante esse lapso temporal delimitado no estudo. A respeito do IDH, destacam-se os componentes educação, saúde e renda, que têm sua origem no Relatório de Desenvolvimento Humano do Programa das Nações Unidades para o Desenvolvimento (PNUD). No tocante ao IFDM, a Federação das Indústrias do Estado do Rio de Janeiro (Firjan), que é a Instituição criadora, em seu sítio oficial, traz as informações necessárias para a compreensão do cálculo desse importante indicador de qualidade de vida. Além da introdução, o artigo é composto por mais quatro seções. A segunda seção é dedica 
à discussão sobre crescimento, desenvolvimento econômico e a industrialização brasileira, enquanto a terceira discute a aplicação de indicadores para a investigação do desenvolvimento. A quarta seção discute os efeitos da atividade industrial nos municípios de Goiatuba e Morrinhos. A quinta e última seção apresenta as considerações finais.

\section{Industrialização, crescimento e desenvolvimento econômico brasileiro}

O desenvolvimento está associado a padrões quantitativos e qualitativos da atividade econômica, pois representa o aumento da oferta de bens e serviços per capita, as modificações das técnicas produtivas, a forma de distribuição dos rendimentos e o comportamento da mão de obra (VIEIRA; SANTOS, 2012). Sob esse prisma, as distinções entre crescimento e desenvolvimento econômico relacionam-se à forma como os resultados são distribuídos e seu potencial de melhorar as condições de vida da população. Entre os fatores necessários tanto para o crescimento econômico quanto para o desenvolvimento econômico está a elevação da produtividade. Porém, a expansão econômica é suscetível a crises aptas a provocar desequilíbrios quanto à produção e distribuição da riqueza.

Neste sentido, manter a constância do crescimento econômico é um dos desafios para subsidiar o desenvolvimento econômico. Siedenberg (2006) define crescimento como um conjunto de alterações de caráter dominantemente quantitativo, expressando aumento, dimensão de volume e/ou quantidade. Acrescida ao conceito de crescimento econômico, soma-se a ampliação da capacidade produtiva e da produção de uma economia em determinado lapso temporal, geralmente calculada pela variação do Produto Nacional Bruto (PNB), que é a soma de todos os bens produzidos e serviços realizados, ou do Produto Interno Bruto (PIB), que é o valor agregado de todos os bens e serviços finais produzidos dentro de um país.

Siedenberg (2006), aponta que o crescimento da renda per capita interfere na vida da sociedade. Para o autor, é imprescindível que o crescimento econômico supere o crescimento demográfico de determinado país ou região, para promover mudanças estruturais pertinentes à melhoraria dos indicadores socioeconômicos. Esses índices estão relacionados ao desenvolvimento econômico, como as questões de caráter social, o bem-estar, nível de consumo, Índice de Desenvolvimento Humano (IDH), taxa de desemprego, analfabetismo e qualidade de vida, entre outros.

As abordagens referentes ao conceito de desenvolvimento remetem à busca de explicar as diversas formas sua relação com a industrialização. Historicamente é perceptível o potencial da industrialização para a geração de emprego e elevação da renda dos trabalhadores. Esse processo pode contribuir no acesso das pessoas 
a melhores condições de alimentação, moradia, lazer, saneamento, dentre outros fatores associados à melhoria da qualidade de vida (VIEIRA, 2009).

Para Furtado (1983, p. 90):

Assim, o conceito de desenvolvimento compreende a ideia de crescimento, superando-a. Com efeito: ele se refere ao crescimento de um conjunto de estrutura complexa. Essa complexidade estrutural não é uma questão de nível tecnológico. $\mathrm{Na}$ verdade, ela traduz a diversidade das formas sociais e econômicas engendrada pela divisão do trabalho social. Porque deve satisfazer às múltiplas necessidades de uma coletividade é que o conjunto econômico nacional apresenta sua grande complexidade de estrutura. Esta sofre a ação permanente de uma multiplicidade de fatores sociais e institucionais que escapam à análise econômica corrente [...] O conceito de crescimento deve ser reservado para exprimir a expansão da produção real no quadro de um subconjunto econômico. Esse crescimento não implica, necessariamente, modificações nas funções de produção, isto é, na forma em que se combinam os fatores no setor produtivo em questão (FURTADO, 1983, p. 90).

Dessa maneira, a visão de Furtado direcionou o debate sobre o desenvolvimento além das questões estritamente econômicas ao considerar a multiplicidade de fatores sociais e institucionais que se esquivam a uma análise puramente econômica. E a passagem do crescimento econômico para o desenvolvimento econômico requer a distribuição dos resultados da elevação da produtividade em bens sociais. Sachs (2004) alinha-se com Furtado ao comentar que:

[...] os objetivos do desenvolvimento vão bem além da mera multiplicação da riqueza material. O crescimento é uma condição necessária, mas de forma alguma suficiente (muito menos é um objetivo em si mesmo) para se alcançar a meta de uma vida melhor, mais feliz e mais completa para todos (SACHS, 2004, p. 13).

A análise estritamente econômica é inepta para explicar a insuficiência do crescimento econômico isoladamente para a produção do desenvolvimento. Essa condição implica na busca de conceitos que possibilitem a adequada compreensão das consequências do crescimento econômico dissociado do desenvolvimento. Entre os recursos para o debate sobre as distinções entre crescimento e desenvolvimento estão as variáveis não econômicas. Sen (2000), converge para essa perspectiva ao identificar que crescimento e desenvolvimento incluem variáveis não econômicas. Para Sen, faz-se necessário considerar a forma como as pessoas podem estar submetidas a diversas formas de privação de liberdade básica 
para a sobrevivência, o que restringe a sua participação no processo de desenvolvimento. $\mathrm{O}$ desenvolvimento de um país estaria diretamente ligado às oportunidades que se oferecem à população de fazer escolhas na prática do exercício da cidadania, garantindo, dessa forma, os direitos sociais básicos, como a saúde, a educação e outros, como segurança, habitação, cultura e lazer. A abordagem de Sen evidencia que a distinção entre crescimento e desenvolvimento se ampara na avaliação das consequências da elevação da produtividade e sua relação com os fatores não econômicos.

A percepção dos fatores econômicos e não econômicos pertinentes à definição das diferenças entre crescimento e desenvolvimento possibilita compreender os efeitos distintos da industrialização nas regiões brasileiras. No Brasil, a alteração do padrão de acumulação no século XX com o deslocamento do setor agrárioexportador para o urbano industrial foi acompanhada pela manutenção da desigualdade social e pela não conversão da expansão da riqueza em desenvolvimento econômico. No país, a instalação de atividades industriais significativas no século XX correlaciona-se a um processo de industrialização tardia, o que fez com que as indústrias ficassem limitadas e incompletas especialmente pela falta de potencialidade dos setores de bens de capital. $\mathrm{O}$ impulso para a industrialização decorreu do investimento do excedente derivado da cafeicultura (CANO, 2007). Desde a ascensão de Getúlio Vargas ao poder em 1930 até a Ditadura Civil Militar (1964-1985), sem ignorar a heterogeneidade dos governos do período, o Estado incentivou o processo de industrialização como fator decisivo para desenvolvimento nacional. Porém, a industrialização acentuou os desequilíbrios regionais e está associada à modernização conservadora do Brasil, condição presente nos primórdios da instalação de indústrias no país.

A literatura dedicada à investigação da industrialização do Brasil ressalta como avanço do setor industrial não possibilitou o rompimento com a condição subordinada do país na divisão internacional do trabalho. Tal condição está na gênese da industrialização. Nesse sentido, Suzigan (2000) analisou a limitação do desenvolvimento industrial relacionando-o com a subordinação do capital industrial ao capital cafeeiro e deste ao capital internacional. A relação entre o desenvolvimento da indústria e a expansão do setor cafeeiro não é linear, tal como sugere a interpretação da industrialização liderada pela expansão das exportações.

[...] a ótica do capitalismo tardio substitui a tradicional dicotomia fatores externos versus fatores internos como motores do crescimento, por uma interpretação que visualiza o crescimento da indústria como primordialmente um resultado do processo de acumulação de capital no setor agrícola exportador, o qual, por sua vez, depende da procura externa [...] Assim, o desenvolvimento do capitalismo no comércio do café ao mesmo tempo estimulou o desenvolvimento industrial e impôs limites a esse desenvolvimento (SUZIGAN, 2000, p. 35-37). 
Observa-se que os efeitos da industrialização se relacionam a dinâmicas sociais, políticas e econômicas pertinentes à inserção do país na divisão internacional do trabalho e aos processos correspondentes à história brasileira. Mensurar o impacto da industrialização implica no reconhecimento das condições históricas que delinearam a sua trajetória no Brasil, considerando a heterogeneidade regional.

Nesse sentido, a análise de processos de industrialização regional ou locais necessariamente deve considerar esse cenário historicamente constituído, bem como as características das atividades industriais. Os limites do presente trabalho implicam na limitação do debate teórico as relações e distinções entre crescimento econômico, desenvolvimento econômico e industrialização. Os parâmetros elencados no presente artigo delineiam a complexidade do tema e as condições de contribuição da industrialização para o desenvolvimento brasileiro.

Essa perspectiva possibilita compreender os efeitos da industrialização ou das ações relacionadas à sua efetivação tendo como parâmetro a leitura crítica dos indicadores econômicos, inclusive sob a perspectiva da tributação e da obtenção dos recursos necessários à efetivação das políticas públicas. No debate sobre o desenvolvimento econômico a industrialização é percebida como um processo que ao produzir crescimento econômicos possibilita a elevação da arrecadação e, portanto, a ampliação das políticas públicas necessárias a satisfação dos parâmetros adequados para a ampliação do bem-estar social. Deste modo, a avaliação do desenvolvimento regional ou local pode ser feita considerando os dados de indicadores econômicos como o Produto Interno Bruto (PIB), e financeiros, como os impostos de uma determinada região. Essas informações tributárias são extraídas das Contas Econômicas ou também chamadas Contas Nacionais, que denotam o núcleo central do Sistema de Contas Nacionais, pois consistem em uma sequência de contas de fluxos inter-relacionadas, detalhadas por setor institucional, demonstrando os dados estatísticos por atividade econômica: demografia, agropecuária, indústria, comércio, serviços, construção civil, transportes, entre outros (IBGE, 2016).

A relação entre os efeitos da industrialização e as políticas públicas amparadas no sistema tributário brasileiro decorrem das determinações da Constituição Federal de 1988, que em seu preâmbulo institui um Estado Democrático, cabendo-lhe assegurar e garantir o exercício dos direitos sociais e individuais, a liberdade, a segurança, o bem-estar, o desenvolvimento, a igualdade e a justiça. Para isso, o Estado necessita do recolhimento dos tributos para obter recursos para desempenhar suas funções sociais, contribuindo no processo de crescimento e de desenvolvimento econômico da sociedade (BRASIL, 1988). O financiamento do Estado por meio da arrecadação tributária deve possibilitar a efetivação de suas três funções essenciais previstas no artigo $3^{\circ}$ da Constituição Federal de 1988 como objetivos fundamentais da República Federativa do Brasil: i) garantir os 
recursos necessários para realização de seus fins; ii) ser instrumento de distribuição de renda e indutor do desenvolvimento social do País; e iii) contribuir para minimizar as diferenças regionais (BRASIL, 1988).

Para Piketty (1997), a tributação é o mecanismo mais eficaz de redistribuição de riquezas destinada ao combate das desigualdades sociais:

O instrumento privilegiado da redistribuição pura é a redistribuição fiscal, que, por meio das tributações e transferências, permite corrigir a desigualdade das rendas produzida pelas desigualdades das dotações iniciais e pelas forças do mercado, ao mesmo tempo que preserva ao máximo a função alocativa do sistema de preços (PIKETTY, 2015, p. 85).

Para Piketty (2014), o processo de estruturação do Estado fiscal e social foi nos países desenvolvidos um fator essencial do processo de modernização e de desenvolvimento nacional. $\mathrm{O}$ autor ressalta o interesse do capital globalizado ao escolher países de baixa tributação para os seus investimentos, tendo como efeito a redução do desenvolvimento social e econômico, especialmente nos países em desenvolvimento.

No Brasil, a carga tributária recebeu incremento desde que foi promulgada a Constituição Federal de 1988, com a ampliação do fenômeno das contribuições parafiscais, com o intuito de contribuir principalmente para as instalações industriais (MACHADO, 1999). Conforme dispõem os artigos $5^{\circ}$ do Código Tributário Nacional (1966) e 145 da Constituição Federal (BRASIL, 1988), o tributo é classificado, de acordo com a sua espécie, em: i) impostos; ii) taxas; iii) contribuições de melhoria (BRASIL, 1966).

Machado (1999) explana sobre a forma como os tributos são distribuídos, pois podem ser vinculados ou não vinculados. Os tributos vinculados são aqueles cuja cobrança se motiva pela existência de uma determinada atividade do Estado, realizada para um contribuinte em especial e não para toda a coletividade, beneficiando-o de alguma forma. São as taxas e as contribuições de melhoria. Enquanto os tributos não vinculados são aqueles cobrados pelo Estado sem a exigência da contraprestação de serviços ou obras ao contribuinte em específico. O Estado cobra esse tipo de tributo para obter recursos para financiar suas atividades estatais (MACHADO, 1999). Para que o Estado cumpra com sua função social, são fundamentais as arrecadações tributárias, os repasses de recursos entre os entes federativos que são primordiais para custear a organização estatal, contribuindo para que o Poder Público, em suas esferas de governo, possa definir políticas públicas para o crescimento e o desenvolvimento da sociedade, auxiliando-o a cumprir suas metas (ALMEIDA, 2014). 
A arrecadação tributária realizada pelos contribuintes aos Entes tributantes colabora para que a função social do tributo seja praticada dentro da sociedade, com a finalidade de atingir o bem-estar e melhorar a distributividade. Dessa forma, coopera para a construção de uma sociedade justa, promovendo, também, o desenvolvimento nacional e possibilita obter recursos para serem destinados com o intuito de erradicar a pobreza e a marginalização, reduzindo as desigualdades sociais e regionais. Portanto, os tributos representam as fontes de custeio para que o Estado possa empregar o que arrecada em benefícios coletivos (MACHADO, 1999).

Assim, a tributação torna-se imprescindível para o desenvolvimento socioeconômico. Vieira (2009) relata que muitos municípios adotam políticas de atração industrial, ao conceder incentivos fiscais, isenção de taxas municipais, doação de terrenos e criação de distritos industriais, dentre outros benefícios, com o intuito de promover o crescimento e o desenvolvimento econômico para sua região, com a concepção de que a industrialização gera arrecadação tributária, mas, principalmente, contribui para o aumento da oferta de emprego e de renda.

As políticas de incentivos fiscais no processo de atração de algo que interessa ao Poder Público são denominadas no Direito Tributário como extrafiscalidade. Ela pode ser considerada um dispositivo que o Estado utiliza para ir além da expansão da sua receita diante dos recolhimentos tributários, mas, também, para investir outros valores constitucionais, como a geração de empregos, por exemplo. Isso se deve ao pelo fato de que os governos podem oferecer isenções, benefícios fiscais, progressividade de alíquotas, principalmente para atrair empresas para que se instalem em seus territórios, com a intenção não propriamente de arrecadar, mas com a finalidade que essas organizações colaborem na oferta de empregos, contribuindo, assim, tanto para o crescimento quanto para o desenvolvimento local (MACHADO, 1999).

Nessa vertente de divisões das entidades tributantes, o Imposto Sobre Serviços De Qualquer Natureza (ISSQN), que se encontra regulamentado pela Lei Complementar $\mathrm{n}^{\circ} 116$, de 31 de julho de 2003, traz a determinação da competência de tributar aos municípios e ao Distrito Federal. Horta (2000) cita a autonomia dos municípios em expedir normas no campo financeiro, como, por exemplo, o estabelecimento dos percentuais das alíquotas que serão aplicadas nas bases de cálculo para o recolhimento do referido imposto e que podem variar entre $2 \%$ a $5 \%$ de município para município. Outro tributo que as indústrias recolhem aos cofres públicos é o Imposto sobre Produtos Industrializados (IPI), que pode ser considerado um relevante mecanismo tributário na intervenção nos setores da economia, pois ele pode tanto estimular quanto desestimular o processo produtivo industrial. Por fim, o Imposto sobre Operações Relativas à Circulação de Mercadorias e sobre Prestações de Serviços de Transporte Interestadual, Intermunicipal, Energia Elétrica e de Comunicação (ICMS) é um tributo de 
competência dos Estados e do Distrito Federal, conforme previsão do art. 155, inciso II, da Constituição Federal de 1988.

A atração de indústrias para possibilitar a expansão da arrecadação e o consequente financiamento das políticas públicas tem como pressuposto que o processo de industrialização pode interferir nos indicadores econômicos e financeiros do país, do estado ou do município, que podem ser quantificados em números, como no Produto Interno Bruto (PIB), e nos tributos que são gerados pelas atividades industriais, contribuir para a melhoria da arrecadação aos cofres públicos e permitindo que o poder público possa investir mais na promoção do desenvolvimento. Porém, a trajetória brasileira, delineada por desigualdade social e econômica e desequilíbrios regionais e intrarregionais denota a pertinência de se investigar como a efetivação dessas premissas é complexa e pode resultar em efeitos distintos do efetivo desenvolvimento econômico. E um dos recursos à disposição para a compreensão dos efeitos da industrialização em escala regional é o uso de indicadores de desenvolvimento e a comparação dos resultados obtidos com as políticas públicas implantadas.

\section{Indicadores de desenvolvimento e as políticas públicas}

De acordo com o Programa das Nações Unidas para o Desenvolvimento (PNUD) a criação do Índice de Desenvolvimento Humano (IDH) busca criar condições para que não se quantificassem apenas os indicadores econômicos que apresentam o crescimento econômico, mas outros para identificar as condições humanas em que a população se encontra. O Índice de Desenvolvimento Humano (IDH) não abarca todas as variáveis possíveis que podem promover o desenvolvimento, como, por exemplo, não calcula a satisfação das pessoas nem indica o melhor lugar no mundo para se viver. A democracia, a participação, a equidade, a sustentabilidade são outras diretrizes não contempladas no cálculo desse índice (PNUD, 2010).

O Índice de Desenvolvimento Humano (IDH) tem como finalidade demonstrar informações referentes aos níveis de educação, longevidade e renda, não se estendendo aos volumes de recursos e às políticas públicas implementadas necessários a elevação o IDH em relação aos índices passados. Para se obter mais informações quanto aos níveis de desenvolvimento de cada município brasileiro foi criado o Índice de Desenvolvimento Humano Municipal (IDHM), que segue a metodologia do IDH (REZENDE; SLOMSKI; CORRAR, 2005). A partir do ano de 2013, o IDHM passou a adotar uma nova metodologia e, com isso, o PNUD relata que não se pode fazer um comparativo do IDHM de um município com o IDH de um país, pois o IDHM tem como inspiração o IDH, mas se diferencia do cálculo em função dos ajustes que sofre para melhor se adequar à realidade brasileira. A metodologia pode ser observada no Quadro 1 (PNUD, 2010). 


\section{Quadro 1 - Variáveis da nova metodologia IDHM Brasil a partir do ano 2013}

\begin{tabular}{|c|c|c|c|c|}
\hline \multirow{3}{*}{$\begin{array}{l}\text { IDHM } \\
\text { Brasil } \\
2013\end{array}$} & \multirow{2}{*}{ Longevidade } & \multicolumn{2}{|r|}{ Educação } & \multirow{2}{*}{ Renda } \\
\hline & & População Adulta & População Jovem & \\
\hline & $\begin{array}{l}\text { Esperança de } \\
\text { vida ao nascer }\end{array}$ & $\begin{array}{l}18 \text { (anos) }+ \text { com } \\
\text { fundamental } \\
\text { completo (peso 1) }\end{array}$ & $\begin{array}{l}\% \text { 5-6 (anos) na escola } \\
\% \text { 11-13 (anos) finais do } \\
\text { fundamental } \\
\% \text { 15-17 (anos) com fundamental } \\
\text { completo } \\
\% \text { 18-20 (anos) com médio } \\
\text { completo (peso } 2 \text { ) }\end{array}$ & $\begin{array}{l}\text { Padrão de } \\
\text { vida / renda } \\
\text { mensal per } \\
\text { capita (em } \\
\text { R\$ ago. / } \\
2010 \text { ) }\end{array}$ \\
\hline
\end{tabular}

Fonte: PNUD (2010).

No site oficial da Federação das Indústrias do Estado do Rio de Janeiro (Firjan), encontram-se informações do Índice Firjan de Desenvolvimento Municipal (IFDM). A Federação tem cobertura nacional. Dispõe de periocidade anual com recorte municipal e utiliza dados fornecidos por outras bases estatísticas públicas oficiais: Instituto Brasileiro de Geografia e Estatística (IBGE), Ministério da Educação e Cultura (MEC), Ministério da Saúde (MS), Ministério do Trabalho e Emprego (MTE), dentre outras. As variáveis dos dados utilizados para se apurar o IFDM podem ser observadas no Quadro 2, disponibilizado no sítio eletrônico da Federação das Indústrias do Estado do Rio de Janeiro (FIRJAN, 2016):

\section{Quadro 2 - Resumo das variáveis componentes do IFDM Firjan por Área de Desenvolvimento}

\begin{tabular}{|c|c|c|}
\hline Saúde & Educação & Emprego e renda \\
\hline Número de consultas pré-natal & Matrículas na educação infantil & Geração de emprego formal \\
\hline $\begin{array}{l}\text { Óbitos por causas mal } \\
\text { definidas }\end{array}$ & $\begin{array}{l}\text { Abandono no ensino } \\
\text { fundamental }\end{array}$ & Absorção da mão de obra local \\
\hline $\begin{array}{l}\text { Óbitos infantis por causas } \\
\text { evitáveis }\end{array}$ & $\begin{array}{l}\text { Distorção idade-série no ensino } \\
\text { fundamental }\end{array}$ & Geração de renda formal \\
\hline $\begin{array}{l}\text { Internação sensível à atenção } \\
\text { básica }\end{array}$ & $\begin{array}{l}\text { Docentes com ensino superior } \\
\text { no ensino fundamental }\end{array}$ & $\begin{array}{l}\text { Salários médios do emprego } \\
\text { formal }\end{array}$ \\
\hline- & $\begin{array}{l}\text { Média de horas aula diárias no } \\
\text { ensino fundamental }\end{array}$ & Desigualdade \\
\hline- & $\begin{array}{l}\text { Resultado do IDEB no ensino } \\
\text { fundamental }\end{array}$ & - \\
\hline Fonte: Ministério da Saúde & Fonte: Ministério da Educação & $\begin{array}{l}\text { Fonte: Ministério do Trabalho e } \\
\text { Emprego }\end{array}$ \\
\hline
\end{tabular}

Fonte: FIRJAN (2016). 
A formulação e a implementação de políticas públicas correspondem ao estabelecer de premissas que contribuam para a melhoria das condições de vida da sociedade. Podem ser subsidiadas por indicadores de desenvolvimento, demonstrando que a participação do poder público é fundamental para uma transformação social (JANNUZZI, 2002). Para que sejam efetivas, é necessário que essas políticas: $\mathrm{i}$ - levem em conta o dia a dia dos indivíduos, em suas ações e peculiaridades; ii - sejam políticas empoderadoras, fornecendo opções e cursos diferenciados de ação às pessoas; iii - respeitem a diversidade dos indivíduos e a realização dessas políticas de acordo com as condições de cada um; iv contemplem micropolíticas baseadas em pequenas ações, mas que podem ter grandes efeitos, se feitas por mais gente ou persistentemente no tempo (PNUD, 2013).

As políticas são habitualmente chamadas de "públicas", quando abordam ações governamentais, entendidas como metas da atividade política. O entendimento do "ser público" inicia-se muito além do ser coletivo, mais do que alcança o poder oriundo da autoridade soberana do governo legitimada pela ação política. As políticas públicas dizem respeito aos fins e aos desejos de uma comunidade bem como aos meios que são definidos para a sua realização (PNUD, 2010).

\section{Efeitos da industrialização em Goiatuba e Morrinhos}

Os municípios de Goiatuba e Morrinhos fazem parte da microrregião do Rio Meia Ponte, da mesorregião Sul do estado de Goiás, delimitando-se aos municípios de Goiatuba e Morrinhos. A investigação compreende o período entre 2000 e 2010. Estabeleceu-se essa década para serem observados os reflexos da industrialização no crescimento e no desenvolvimento dos respectivos municípios, com ênfase nos indicadores socioeconômicos.

A distância entre os dois municípios é de 55,4 quilômetros. Apesar de próximos, um deles apresenta um polo industrial maior que o outro. Por essa razão, o presente estudo considerou relevante verificar o crescimento e o desenvolvimento desses dois munícipios relacionados com o fenômeno da industrialização. Para isso, considerou-se o debate que distingue crescimento e desenvolvimento a partir dos indicadores socioeconômicos, com a finalidade de proporcionar um resultado que verifique a forma como a industrialização impactou nos municípios de Goiatuba e Morrinhos, os quais, no início da década de 2000, apresentavam uma população muito próxima, conforme Tabela 1. 
Tabela 1 - Dados populacionais de Goiatuba (GO) e Morrinhos (GO), 2000-2010

\begin{tabular}{lccc}
\hline Municípios & População (2000) & População (2010) & Variação em \% \\
\hline Goiatuba & 31.130 & 32.492 & $+4,38$ \\
\hline Morrinhos & 36.990 & 41.460 & $+12,08$ \\
\hline
\end{tabular}

Fonte: IPEA (2015).

No decorrer da década de 2000, Morrinhos (GO) apresentou um aumento na população e, também, em relação à atratividade de indústrias instaladas em comparação a Goiatuba (GO). De acordo com a base pública Empresas do Brasil, durante a década de 2000 cinco industrias instalaram-se em Goiatuba, enquanto 19 foram implantadas em Morrinhos. Tal resultado está relacionado aos incentivos da implementação de políticas públicas, com destaque para a política tributária como atrativo.

O PIB é o indicador que evidencia o valor agregado de todos os bens e serviços finais produzidos no território econômico. Vieira (2009) cita que o crescimento de uma economia é indicado ainda pelo crescimento de sua força de trabalho; a receita nacional poupada é investida; e o grau de aperfeiçoamento tecnológico.

Tabela 2 - Variação do crescimento econômico dos municípios de Goiatuba (GO) e Morrinhos, 2000-2010

\begin{tabular}{l|cccccc}
\hline & \multicolumn{3}{|c}{ Goiatuba } & \multicolumn{3}{c}{ Morrinhos } \\
\cline { 2 - 7 } & 2000 & 2010 & $\begin{array}{c}\text { Variação } \\
\%\end{array}$ & 2000 & 2010 & $\begin{array}{c}\text { Variação } \\
\%\end{array}$ \\
\hline $\begin{array}{l}\text { Produto Interno Bruto a } \\
\text { Preços Correntes (R mil) }\end{array}$ & $431.398,54$ & $695.391,00$ & 61,19 & $352.950,25$ & $653.866,00$ & 85,26 \\
\hline $\begin{array}{l}\text { Produto Interno Bruto } \\
\text { per Capita (R\$) }\end{array}$ & $13.821,57$ & $21.409,10$ & 54,90 & $9.469,08$ & $15.772,10$ & 66,56 \\
\hline
\end{tabular}

Fonte: IMB; valores atualizados em $\mathrm{R} \$$ de 2010 deflacionados pelo IPCA do IBGE (2016).

Ao traçar um comparativo entre os municípios estudados no que se refere ao PIB a Preços Correntes, verifica-se que o Morrinhos (GO) apresentou no final da década de 2000 uma variação 24,07\% maior do que a de Goiatuba (GO). Quanto ao PIB per capita, também apresentou uma variação maior que chegou ao percentual de $11,66 \%$ conforme Tabela 2 , o que pode ser atribuída à 
industrialização como fator importante ao município que apresentou melhor crescimento.

O estudo da participação da industrialização para o crescimento e desenvolvimento regional permitiu elaborar um comparativo que diz respeito ao PIB dos municípios pesquisados com o percentual atingido pela Microrregião do Rio Meia Ponte (GO) e do estado de Goiás no período de 2000 a 2010, como pode ser observado na Tabela 3. O município de Morrinhos (GO) se sobressai apresentando o melhor resultado de industrialização, com 30,69\% a mais que Goiatuba (GO).

Tabela 3 - Variação do PIB Municipal industrial, 2000-2010

\begin{tabular}{lrrc}
\hline Localidades & $\begin{array}{c}\text { PIB Municipal - indústria - } \\
\text { valor adicionado - preços } \\
\text { básicos (2000) }\end{array}$ & $\begin{array}{c}\text { PIB Municipal - indústria - } \\
\text { valor adicionado - preços } \\
\text { básicos (2010) }\end{array}$ & $\begin{array}{c}\text { Variação do } \\
\text { crescimento } \\
\text { econômico (\%) }\end{array}$ \\
\hline Goiatuba & $51.257,17$ & $71.445,52$ & $+39,39$ \\
Morrinhos & $33.928,29$ & $57.704,65$ & $+70,08$ \\
Microrregião do & $521.952,02$ & $729.509,79$ & $+39,77$ \\
Rio Meia Ponte & $5.551 .667,31$ & & \\
Estado de Goiás & & $10.055 .756,72$ & $+81,13$ \\
\hline
\end{tabular}

Fonte: IPEA; valores atualizados em R $\$$ de 2010 deflacionados pelo IPCA do IBGE (2016).

O PIB municipal industrial na década de 2000 destaca que Morrinhos (GO) cresceu e quase atingiu o dobro de Goiatuba (GO). Superou a Microrregião do Rio Meia Ponte e ficou bem próximo do crescimento econômico alcançado pelo estado de Goiás.

Os indicadores econômicos e financeiros refletem as ações do município de Morrinhos (GO), por conta de leis como a Lei Orgânica $n^{\circ}$ 901, de 05 de abril de 1990, a Lei $\mathrm{n}^{\circ} 1.781$, de 14 de dezembro de 2000, a Lei $\mathrm{n}^{\circ} 13.591$, de 18 de janeiro de 2000, e a Lei $\mathrm{n}^{\circ}$ 2.281, de 29 de janeiro de 2007, todas voltadas para a atratividade de indústrias. No período analisado, Morrinhos apresentou maior crescimento econômico. Goiatuba (GO), por sua vez, faz menção ao processo de atração industrial em sua Lei Orgânica n ${ }^{\circ}$ 20, de 4 de agosto de 2010, porém não estabelece definitivamente meios para essa atração. O crescimento pode ser visualizado nas tabelas a seguir: 
Tabela 4 - Variação da arrecadação do ISSQN, 2000-2010

\begin{tabular}{lrrc}
\hline Localidades & ISSQN (2000) & ISSQN (2010) & Variação da arrecadação ISSQN (\%) \\
\hline Goiatuba & $482.451,43$ & $1.343 .482,00$ & 178,47 \\
\hline Morrinhos & $1.012 .753,45$ & $3.579 .850,00$ & 253,48 \\
\hline
\end{tabular}

Fonte: IPEA; valores atualizados em $\mathrm{R} \$$ de 2010 deflacionados pelo IPCA do IBGE (2016).

A variação do ISSQN evidencia o impulso da industrialização em Morrinhos, com a obtenção de uma arrecadação significativamente superior em comparação à Goiatuba. A mesma característica está presente na Tabela 5 , quanto à variação da arrecadação de ambos municípios no período analisado.

Tabela 5 - Variação da arrecadação do ICMS, 2000-2010

\begin{tabular}{lccc}
\hline Localidades & ICMS (2000) & ICMS (2010) & Variação da arrecadação ICMS (\%) \\
\hline Goiatuba & $16.873 .960,00$ & $12.410 .210,00$ & $-26,45$ \\
\hline Morrinhos & $6.477 .864,00$ & $14.321 .024,00$ & 121,08 \\
\hline
\end{tabular}

Fonte: IPEA; valores atualizados em $\mathrm{R} \$$ de 2010 deflacionados pelo IPCA do IBGE (2016).

Diante do exposto, podem ser visualizadas maiores variações econômicas para Morrinhos (GO). Todavia, em relação ao IFDM, que é o índice utilizado para demonstrar o desenvolvimento dos municípios, a industrialização não foi um fator crucial para que Morrinhos (GO) continuasse à frente de Goiatuba (GO), como pode ser visualizado no Gráfico 1: 


\section{Gráfico 1 - Índice Firjan de Desenvolvimento Municipal de Morrinhos (GO) e Goiatuba (GO), 2010}

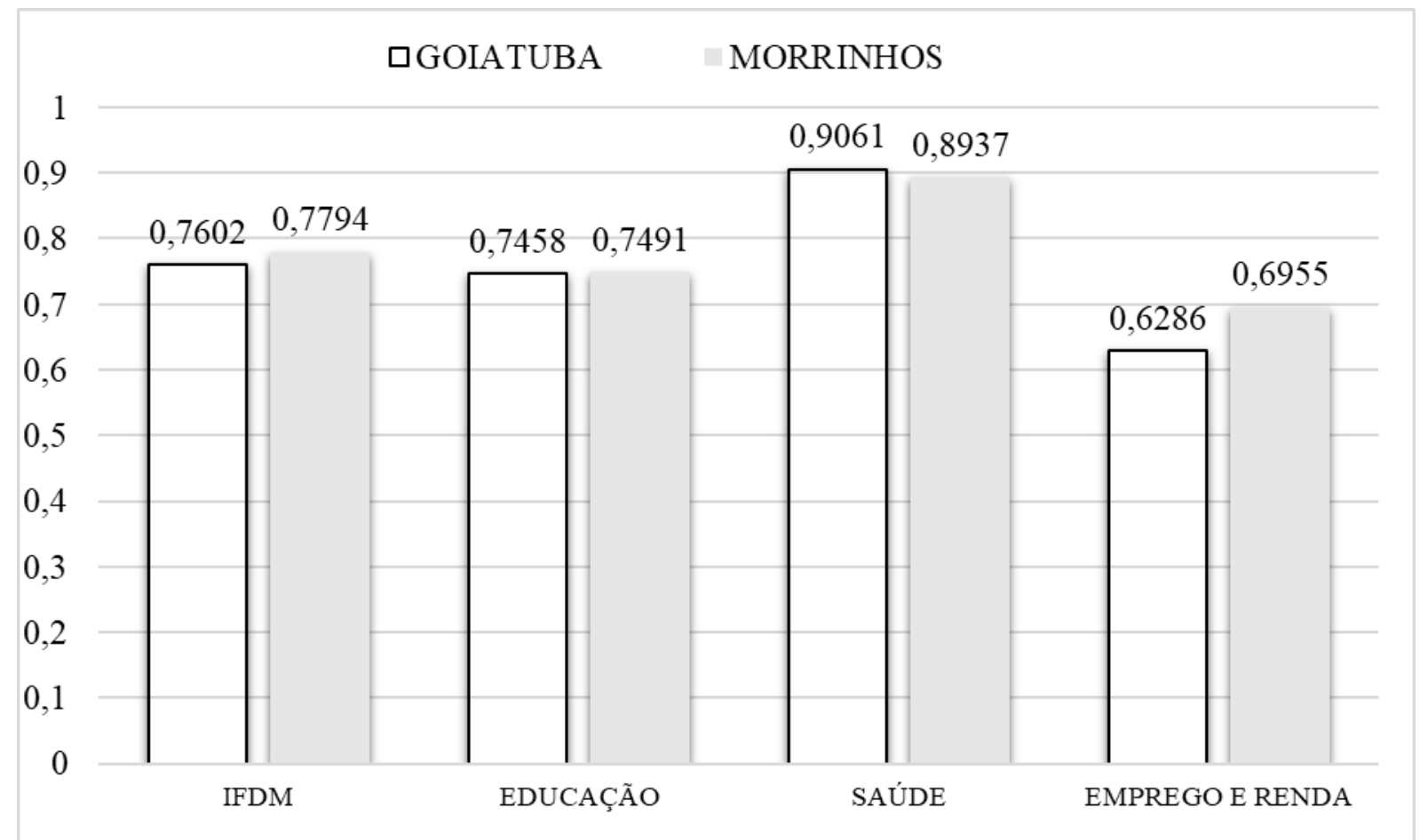

Fonte: IFDM (FIRJAN, 2016).

Apesar de o município de Morrinhos ser mais industrializado, os percentuais dos indicadores de desenvolvimento continuaram próximos aos de Goiatuba, confirmando, mais uma vez, que o processo de industrialização não foi determinante para o desenvolvimento do município. Em relação ao IDHM, que é um índice que retrata a situação dos municípios em relação à educação, à longevidade e à renda, também os municípios se mostraram muito próximos. Portanto, a industrialização de Morrinhos não contribuiu o suficiente para a elevação dos seus indicadores de desenvolvimento em comparação à Goiatuba.

Observa-se que os limites da presente pesquisa não possibilitam a inclusão de outras varáveis como a contribuição das políticas públicas dos governos federal e estadual e também os efeitos do crescimento econômico do país no período analisado. A comparação evidencia que a industrialização corresponde a um dos fatores relacionados ao desenvolvimento, mas não o único. Outras variáveis estão imbricadas na elevação da qualidade de vida mensurada pelos indicadores usualmente utilizados para esse fim, como sugere o resultado da comparação entre Morrinhos e Goiatuba. 
Tabela 6 - Comparativo do Índice de Desenvolvimento Municipal, 20002010

\begin{tabular}{lcccc}
\hline IDHM e componentes & \multicolumn{2}{c}{ Goiatuba } & \multicolumn{2}{c}{ Morrinhos } \\
\hline & 2000 & 2010 & 2000 & 2010 \\
\hline IDHM Educação & 0,434 & 0,627 & 0,419 & 0,621 \\
\hline $\begin{array}{l}\text { \% de } 18 \text { anos ou mais com ensino } \\
\text { fundamental completo }\end{array}$ & 33,71 & 48,74 & 32,09 & 47,84 \\
\hline \% de 5 a 6 anos frequentando a escola & 73,13 & 93,03 & 65,89 & 88,47 \\
\hline $\begin{array}{l}\text { \% de } 11 \text { a } 13 \text { anos frequentando os anos } \\
\text { finais do ensino fundamental }\end{array}$ & 66,54 & 89,72 & 68,26 & 90,4 \\
\hline $\begin{array}{l}\text { \% de 15 a 17 anos com ensino } \\
\text { fundamental completo }\end{array}$ & 36,46 & 63,43 & 39,43 & 63,65 \\
\hline $\begin{array}{l}\text { \% de } 18 \text { a 20 anos com ensino médio } \\
\text { completo }\end{array}$ & 18,06 & 38,6 & 18,13 & 40,77 \\
\hline $\begin{array}{l}\text { IDHM Longevidade } \\
\text { Esperança de vida ao nascer (em anos) }\end{array}$ & 73,809 & 0,825 & 0,803 & 0,862 \\
\hline $\begin{array}{l}\text { IDHM Renda } \\
\text { Renda per capita (em R } \$ \text { ) }\end{array}$ & 6,711 & 0,737 & 0,717 & 0,739 \\
\hline
\end{tabular}

Fonte: Adaptado de PNUD (2010).

Assim, denota Jannuzzi (2002), a observância dos indicadores sociais colabora para que os governos possam planejar ações e políticas sociais, amenizando as disparidades sociais. Na ótica de Vieira (2009), o direcionamento das políticas públicas é essencial para a busca do desenvolvimento. É preciso ultrapassar as barreiras econômicas, levando em consideração o bem-estar, ressaltando a saúde, a educação, o acesso ao trabalho e a distribuição da renda.

A partir dos dados obtidos em bases públicas, foi verificado que no município de Morrinhos o processo de industrialização foi mais acentuado em comparação a Goiatuba. O recolhimento dos tributos ao Estado compõe a base de custeio de todos os serviços prestados pelo poder público. A tributação pode ser considerada como uma ferramenta que contribui para que o Estado possa planejar o quanto irá arrecadar de tributos e quanto poderá planejar para investimentos, gastos públicos e, essencialmente, o quanto irá destinar ao desenvolvimento, propiciando melhores condições e acarretando melhoria na qualidade de vida da população. A redução ou renúncia da tributação para atração de indústrias tem como premissa a expansão do emprego e da renda mediante investimentos. Espera-se que o efeito multiplicador estimule o crescimento econômico e favoreça o desenvolvimento local e regional. 
Entretanto, a comparação dos dados pertinentes à Morrinhos e Goiatuba evidencia que a maior industrialização do primeiro tem efeito limitado em comparação ao segundo município, ao menos quando o parâmetro de avaliação é o desenvolvimento enquanto fenômeno multidimensional. Ressalta-se que nesta pesquisa evidenciaram-se somente os tributos gerados pelas atividades industriais, que são: Imposto sobre Serviços de Qualquer Natureza (ISSQN), Imposto sobre Produtos Industrializados (IPI) e o Imposto sobre Operações Relativas à Circulação de Mercadorias e sobre Prestações de Serviços de Transporte Interestadual, Intermunicipal e de Comunicação (ICMS).

Os indicadores econômicos e financeiros também podem refletir que o município de Morrinhos (GO) tem normativas, conforme já mencionado no presente estudo, voltadas para a atratividade de indústrias, utilizando a tributação como uma ferramenta importante nesse processo. Goiatuba (GO) faz menção ao processo de atração industrial, em sua Lei Orgânica no 20 de 4 de agosto de 2010, porém, não estabelece definitivamente meios para essa atração e, sim, que adotará políticas para a instalação das indústrias. Isso pode ter tido por consequência o fato de o município ser menos industrializado e apresentar um crescimento econômico menor do que Morrinhos (GO) na década de 2000.

Além de a pesquisa ter retratado o crescimento econômico, houve o cuidado de avaliar os indicadores que demonstraram desenvolvimento, relacionando-os com o fator industrialização. Durante a pesquisa foi avaliado que a industrialização não contribuiu significativamente para que Morrinhos (GO) apresentasse percentuais de desenvolvimento elevados em relação à Goiatuba. Pelo contrário, mantiveramse muito próximos durante a década de 2000 no IFDM (FIRJAN) referentes à saúde, à educação, ao emprego e à renda. A industrialização contribuiu para o crescimento econômico de Morrinhos (GO) em relação ao de Goiatuba (GO), que se apresentou menos industrializado. Porém, a industrialização não influenciou na melhora dos indicadores de desenvolvimento de Morrinhos (GO), portanto, não é um fator crucial para o desenvolvimento dos municípios.

\section{Considerações finais}

A industrialização foi apresentada na história econômica como um recurso para a promoção do desenvolvimento. Nesse sentido, o presente estudo delimitou como objetivo a identificação do processo de industrialização durante a década de 2000 dos municípios de Goiatuba (GO) e Morrinhos (GO), pertencentes à Microrregião do Rio Meia Ponte (GO), no intuito de verificar a contribuição da industrialização no crescimento e/ou desenvolvimento econômico dos municípios objetos da pesquisa. Buscou-se problematizar como o crescimento econômico a partir da industrialização pode ter efeitos limitados em municípios de pequeno 
porte no interior Goiás na década de 2000, considerando as ações tomadas para a atração de indústrias e os efeitos dessa ação.

A pesquisa delineou a contribuição do processo de industrialização dos municípios de Goiatuba (GO) e Morrinhos (GO), demonstrando os indicadores econômicos com a finalidade de verificar o município que mais se destacou economicamente, entre o período de 2000 a 2010, e, também, os indicadores de desenvolvimento, com a intenção de identificar se a industrialização contribui para a promoção do desenvolvimento. Entretanto, há limites inerentes à metodologia da pesquisa e aos dados utilizados, pois não é possível relativizar totalmente o impacto da industrialização para o desenvolvimento de Morrinhos ou a contribuição das políticas públicas federal e estadual no período de análise, considerando o expressivo crescimento econômico do país naquele momento, o que possibilitou a expansão do investimento público.

A proximidade dos indicadores dos municípios de Goiatuba e Morrinhos indica que as políticas públicas de desenvolvimento em escala municipal têm efeitos limitados em razão da localização e da inserção nos demais níveis de integração econômica como o regional, o estadual e o nacional. Outro aspecto a se considerar relaciona-se aos efeitos das políticas públicas dedicadas especificamente à educação, saúde e segurança em municípios de pequeno porte e como demandas distintas dos centros metropolitanos. Nesse sentido, as ações focadas no aprimoramento da educação pública e serviços da área de saúde podem ter efeitos mais consistentes do que a atração de indústrias e seus efeitos limitados ao crescimento econômico. Os resultados da pesquisa indicam a necessidade de se ampliar o escopo da investigação com a comparação dos indicadores econômicos e de desenvolvimento com instrumentos de verificação correspondentes ao estabelecimento de correlações entre variáveis relacionadas ao escopo da pesquisa realizada, inclusive quanto aos efeitos específicos das políticas públicas. Assim, será possível identificar padrões que permitam distinguir as consequências da industrialização e seus limites quanto a promoção do desenvolvimento local e regional.

\section{Referências}

ALMEIDA, M. L. de. Reflexos de uma concentração produtiva nos indicadores de desenvolvimento do município de Buriti Alegre (GO). 2014. 136 f. Dissertação (Mestrado) - Mestrado em Planejamento e Desenvolvimento Regional, Universidade de Taubaté, São Paulo, 2014.

CANO, W. Desequilíbrios regionais e concentração regional no Brasil (1930-1970). São Paulo: UNESP, 2007. 
BRASIL. Constituição Federal de 1988. Disponível em: <www.planalto.gov.br/ccivil_03/constituicao/constituicaocompilado.htm>. Acesso em: 12 jul. 2016.

BRASIL. Lei N. 5172, de 25 de outubro de 1966. Código Tributário Nacional: Dispõe sobre o Sistema Tributário Nacional e institui normas gerais de direito tributário aplicáveis à União, Estados e Municípios.

FURTADO, C. Teoria e política do desenvolvimento econômico. São Paulo: Abril Cultural, 1983.

HORTA, R. M. Formas simétrica e assimétrica do federalismo no Estado moderno. In: SALDANHA, N. N.; REIS, P. M. (Org.) Estudos jurídicos, políticos e sociais: Homenagem a Glaúcio Veiga. Curitiba: Juruá, 2000, p. 212.

IBGE-Instituto Brasileiro de Geografia e Estatística. Disponível em: <http://www.cidades.ibge.gov.br/xtras/home.php>. Acesso em: 13 jan. 2016.

IFDM-Índice Firjan de Desenvolvimento Municipal. Disponível em: <http://www.Firjan.org.br/ifdm/>. Acesso: em 13 jan. 2016.

IPEA. Banco de dados do IPEADATA. Disponível em: <www.ipeadata.gov.br>. Acesso em: 19 dez. 2015.

JANNUZZI, P. M. Considerações sobre o uso, o mau uso e o abuso dos indicadores sociais na formulação e avaliação de políticas públicas municipais. Revista de Administração Pública. Rio de Janeiro, 36 (1), p. 51-72, jan./fev. 2002. Disponível

em: <http://bibliotecadigital.fgv.br/ojs/index.php/rap/article/view/6427>. Acesso em: 19 jun. 2016.

MACHADO, H. B. Curso de direito tributário. 14 ed. São Paulo: Malheiros, 1999.

PIKET'TY, T. A economia da desigualdade. Trad. André Telles. Rio de Janeiro: Intrínseca, 2015.

PIKETTY, T. O capital do século XXI. Lisboa: Temas e Debates, 2014.

PNUD-Programa das Nações Unidas para o Desenvolvimento. Atlas do desenvolvimento humano no Brasil 2013. Perfil do município de Goiatuba, GO. Disponível em: 
<http://www.pnud.org.br/IDH/Atlas2013.aspx?indiceAccordion=1\&li=li _Atlas2013>. Acesso em: jan. 2017.

PNUD-Programa das Nações Unidas para o Desenvolvimento. Relatório de desenvolvimento humano Brasil 2009/2010: Valores e desenvolvimento humano. Brasília, 2010. Disponível em: <http://www.pnud.org.br/HDR/arquivos/rdh_Brasil_2009_2010.pdf>. Acesso em: 13 jan. 2016.

REZENDE, A. J.; SLOMSKI, V.; CORRAR, L. J. A gestão pública municipal e a eficiência dos gastos públicos: uma investigação empírica entre as políticas públicas e o Índice de Desenvolvimento Humano (IDH) dos municípios do Estado de São Paulo. Revista Universo Contábil, 1(1), 24-40, 2005. Disponível em: <proxy.furb.br/ojs/index.php/universocontabil/article/viewFile/75/3>. Acesso em: 13 jan. 2016.

SACHS, I. Desenvolvimento: includente, sustentável, sustentado. Rio de Janeiro: Garamond, 2004.

SANTOS, E. et al. Desenvolvimento: um conceito multidimensional. DRd: Desenvolvimento Regional em debate, 2 (1), p. 44-61, 2012.

SIEDENBERG, D. R. Dicionário do desenvolvimento regional. Santa Cruz doSul: Edunisc, 2006.

SEN, A. K. Desenvolvimento como liberdade. São Paulo: Companhia de Letras, 2000.

SUZIGAN, W. Indústria brasileira: origens e desenvolvimento. São Paulo: Hucitec; Ed. Unicamp, 2000.

VIEIRA, E. T. Industrialização e políticas de desenvolvimento regional: o Vale do Paraíba paulista na segunda metade do século XX. São Paulo, 2009. Tese (Doutorado em História Econômica) - Universidade de São Paulo.

VIEIRA, E. T.; SANTOS, M. J. dos. Desenvolvimento econômico regional: uma revisão histórica e teórica. Revista Brasileira de Gestão e Desenvolvimento Regional, Taubaté, v. 8, n. 2, p. 344-369, 2012. Disponível em: <http://www.rbgdr.net/revista/index.php/rbgdr/article/view/679>. Acesso em: 12 jun. 2016. 
Endereço para correspondência:

Anne Kelly Aparecida de Souza Tassara - annekelly.aparecida@gmail.com Rodovia GO 320, s/n - Jardim Santa Paula

75600-000 Goiatuba/GO, Brasil

Moacir José dos Santos - professormoacirsantos@gmail.com

Rua Visconde do Rio Branco, 210

12020-040 Taubaté/SP, Brasil

Edson Trajano Vieira - etrajanov@gmail.com

Rua Visconde do Rio Branco, 210

12020-040 Taubaté/SP, Brasil 